\title{
THE SOLUBILITY OF DEXTROSE IN WATER
}

\author{
By Richard F. Jackson and Clara Gillis Silsbee
}

\section{ABSTRACT}

The solubilities of dextrose, in addition to their scientific interest, have become of fundamental importance in controlling the processes of manufacture. They have been determined over a range of temperatures extending to $90^{\circ} \mathrm{C}$. Three solid phases are capable of existence, namely, ice, $\alpha$-dextrose monohydrate, and anhydrous $\alpha$-dextrose. From the freezing point curve, computed from existing data, and the saturation curve of dextrose hydrate, the cryohydric point was found. Dextrose hydrate is stable between $-50^{\circ} 3 \mathrm{C}$ and $50^{\circ} \mathrm{C}$; its solubility has a high temperature coefficient.

The transition from dextrose hydrate to anhydrous dextrose is shown to occur at $50^{\circ} \mathrm{C}$. Above this temperature anhydrous dextrose is the solid phase. Its tempera. ture coefficient is relatively small. Below the transition temperature the anhydrous form may persist in unstable equilibrium, even at a temperature as low as $28^{\circ} \mathrm{C}$.

\section{CONTENTS}

1. Introductory $\ldots \ldots \ldots \ldots \ldots \ldots \ldots \ldots \ldots \ldots \ldots \ldots \ldots \ldots \ldots \ldots \ldots \ldots \ldots \ldots \ldots \ldots$

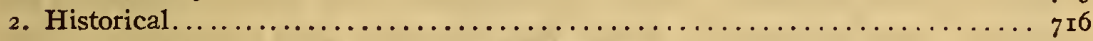

3. General description of solubility measurements................ 7 I6

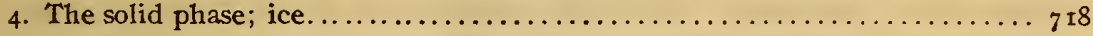

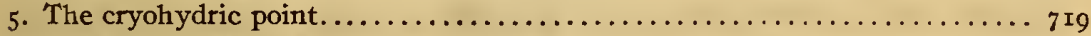

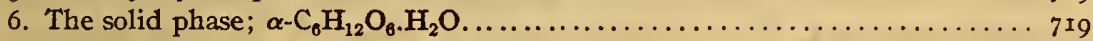

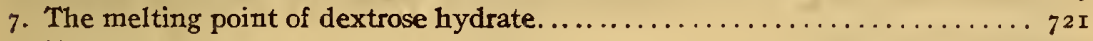

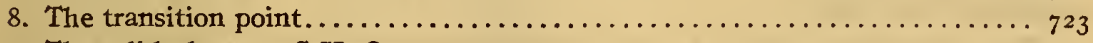

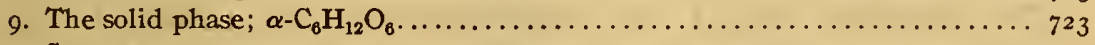

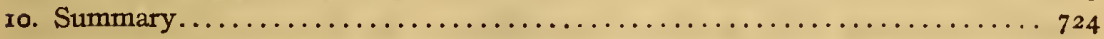

\section{INTRODUCTORY}

In very recent times it has been found commercially feasible to crystallize dextrose from water solution and to separate the crystals from the mother liquor by centrifugal machines in much the same manner as the corresponding step in cane sugar manufacture is carried out. A similar process ${ }^{1}$ was attempted about forty years ago, but the effort resulted in failure. With the advent of modern machinery and more scientific methods, however, the

${ }^{1}$ Making crystalline dextrose, C. E. G. Porst, Sugar, 23, p. 380; 1921. Louisiana Planter, 67, p. 14; July 2, $192 x$. 
industry is at present being revived on a large scale with every prospect of success.

As a fundamental basis for calculating supersaturation coefficients, for estimating crystallizer performance, and the more extended investigation of the effect of nonsugars in the process of crystallization, the solubility of the pure substance in water assumes a technical as well as scientific importance. To serve these purposes we have undertaken the determination of solubilities over a wide range of temperatures.

\section{HISTORICAL}

A survey of the literature revealed but one solubility measurement, and that at only one temperature. Anthon ${ }^{2}$ in 1883 found that at $15^{\circ} \mathrm{C}$ Ioo parts of water dissolved $8 \mathrm{r} .68$ parts of anhydrous dextrose, giving a solution of 44.96 per cent. Aside from this, no data are in existence. Maquenne, ${ }^{3}$ however, states that at $100^{\circ} \mathrm{C}$ dextrose and water are miscible in all proportions.

\section{GENERAL DESCRIPTION OF SOLUBILITY MEASUREMENTS}

The solubility measurements were made by agitating the mixture of dextrose and water with a large proportion of the solid phase in a rotating frame under the water of an electrically operated thermostat. After equilibrium had been reached, the solution was separated from the crystals and analyzed. The separation of the finely divided crystals from the viscous saturated solution was accomplished by filtration under pressure through an asbestos mat, the arrangement of which is shown diagrammatically in Fig. I.

The filtration tube $A$ was constructed of glass tubing $20 \mathrm{~mm}$ inside diameter with walls $3 \mathrm{~mm}$ thick. In this was inserted the perforated brass disc $B$ which was edged with lead and covered with an asbestos mat. For temperatures much removed from that of the laboratory, the transference from the solubility bottle $C$ was accomplished as shown in position $I$. The solubility bottle was removed from the rotating frame with a pair of tongs and its mouth held above the liquid of the thermostat and wiped dry. A rubber stopper was inserted which carried the wide bore glass tube $D$, which extended nearly to the bottom of the bottle. The glass tube passed through another stopper into the filtration tube,

2 V. Lippmann, Die chemie der zuckerarten, 1, p. 266; x904.

3 Les suctes et principaux dérivés, p. 479; 1900. 


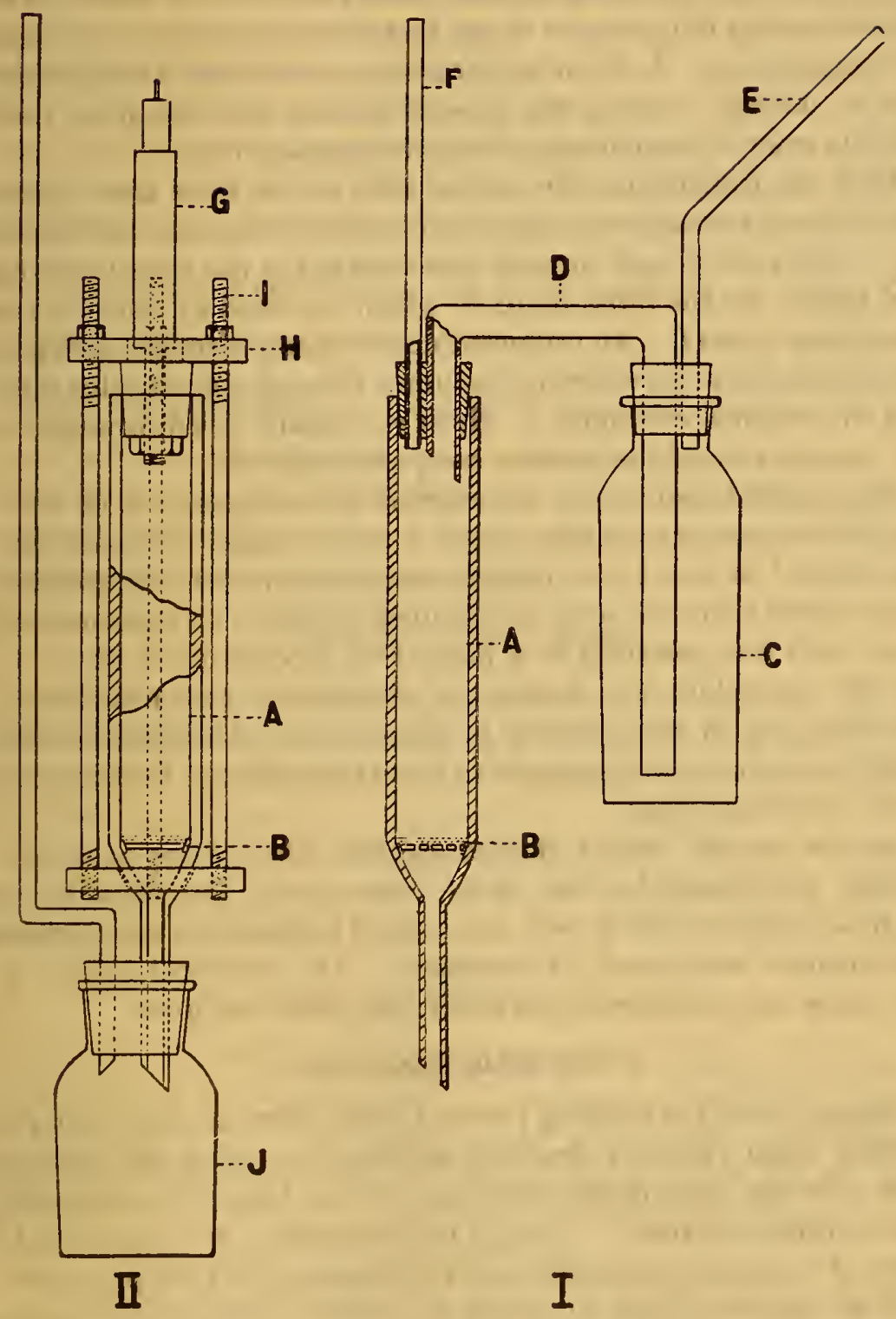

Fig. I.-Apparatus for filtration of viscous solutions under pressure $93045^{\circ}-22-2$ 
the latter being arranged with respect to the remaining parts or the apparatus as shown in position $I I$, with the exception of the valve $G$ and brass plate $H$. The whole apparatus, with the exception of the upper parts of the two small glass tubes $E$ and $F$, was then immersed in the water of the thermostat and allowed to take its temperature. A slight air pressure transmitted through the tube $E$ sufficed to drive the crystal mixture into the filter tube without even a momentary change in temperature.

After the transference the upper edge of the filter tube $A$ was raised above the surface of the liquid of the thermostat and wiped dry. The valve $G$ and stopper were inserted in the filter tube and held tightly by the brass plate $H$, which was held in place by the three brass posts $I$. An ordinary bicycle pump supplied sufficient pressure to force the saturated solution through the asbestos filter into the weighed container $J$, which was finally dried, brought to the temperature of the balance case, and weighed.

The weighed sample was transferred to a weighed roo cc volumetric flask, made to volume at $20^{\circ} \mathrm{C}$ and weighed. The solution was allowed to stand over night in order to complete the mutarotation which occurs to some extent upon dilution of a concentrated syrup, and was polarized in a Bates-Frič saccharimeter at $20^{\circ} \mathrm{C}$. By this procedure we obtained a densimetric and polariscopic determination of the dextrose in the sample. An agreement by these two methods was assumed to be an indication of the accuracy of the analytical work.

For the normal weight of dextrose the value $32.23 \mathrm{I} \mathrm{g}$, as previously determined by one of us, ${ }^{4}$ was used. The densities of dextrose solutions which were determined incidentally to this same investigation were used as standards. All analytical results in this paper are expressed in terms of anhydrous dextrose.

\section{THE SOLID PHASE; ICE}

Starting with the freezing point of pure water we may plot the freezing point curve of dextrose solutions by using the data of Roth ${ }^{5}$ for the more dilute solutions, and of Abegg ${ }^{6}$ for the more concentrated solutions. Abegg's determinations are expressed in terms of volume concentrations at the freezing point temperatures, with no accessory data by which to calculate the concentrations by weight. It was consequently necessary to determine the densi-

1 Jackson, B. S. Bulletin, 13, p. 633, 1916 (or B. S. Sci. Papers, No. 293).

- I,andolt and Börnstein Tabellen, p. 820; 1912.

2 Zeit. Phys. Chem., 15, 222; 1894. 
ties of the solutions which possessed the same concentrations per volume at the respective temperatures as those concerned in his freezing point determinations. Two such solutions were prepared and their densities at $0^{\circ} \mathrm{C}$ and their expansion coefficients were accurately determined. From these data their densities and volume concentrations were computed for the temperatures at which Abegg's freezing point determinations were made. In both cases the volume concentrations as thus determined approximated Abegg's very closely, and a slight interpolation to his precise concentration was possible without appreciable error. The solution containing $188.02 \mathrm{~g}$ per liter at $-2: 305 \mathrm{C}$ had a density $\left(\frac{-2: 305 \mathrm{C}}{4^{\circ} \mathrm{C}}\right)$ of $\mathrm{I} .0740$ and a weight composition of $\mathrm{I} 7.586$ per cent; that containing $378.0 \mathrm{~g}$ per liter at $-5^{\circ} .605 \mathrm{C}$ had a density $\left(\frac{-5^{\circ} \cdot 605 \mathrm{C}}{4^{\circ} \mathrm{C}}\right)$ of I. I 464 and a weight composition of 33.015 per cent.

The above data are plotted in Fig. 2. The essential agreement between Roth's and Abegg's determinations is shown by the smoothness of the connecting curve.

\section{THE CRYOHYDRIC POINT}

At the intersection of the freezing point curve with the extrapolated solubility curve of hydrated dextrose occurs the cryohydric point. The temperature and composition as determined graphically proved to be $-5{ }^{\circ} \mathrm{C}$ and $3 \mathrm{I} .75$ per cent.

Since no solubility measurements were made below $0^{\circ} \mathrm{C}$, the possibility is not excluded that a new solid phase may be stable between $\mathrm{o}$ and $-5: 3 \mathrm{C}$.

\section{SOLID PHASE; $\alpha-\mathrm{C}_{6} \mathrm{H}_{12} \mathrm{O}_{6} \cdot \mathrm{H}_{2} \mathrm{O}$}

At and above the cryohydric temperature the stable solid phase of the sugar is the monohydrate. The region of stability of this phase extends from $-5 \circ 3 \mathrm{C}$ to exactly $50^{\circ} \mathrm{C}$. The solubilities are assembled in Table $\mathrm{I}$ and are shown graphically in Fig. 2. As appears from the diagram, Anthon's solubility measurement at $15^{\circ} \mathrm{C}$ is in good agreement with our curve.

This phase on crystallization from water solution in general forms minute plates of a lustrous silky appearance. The crystals, however, are capable of good development. We are informed by Mr. W. B. Newkirk, of the Corn Products Refining Co., that when 
the substance is allowed to crystallize slowly during the process of large scale manufacture, crystals of considerable magnitude are obtained. Mr. F. P. Phelps, of this Bureau, has succeeded in growing perfectly formed crystals $6-7 \mathrm{~mm}$ in length.

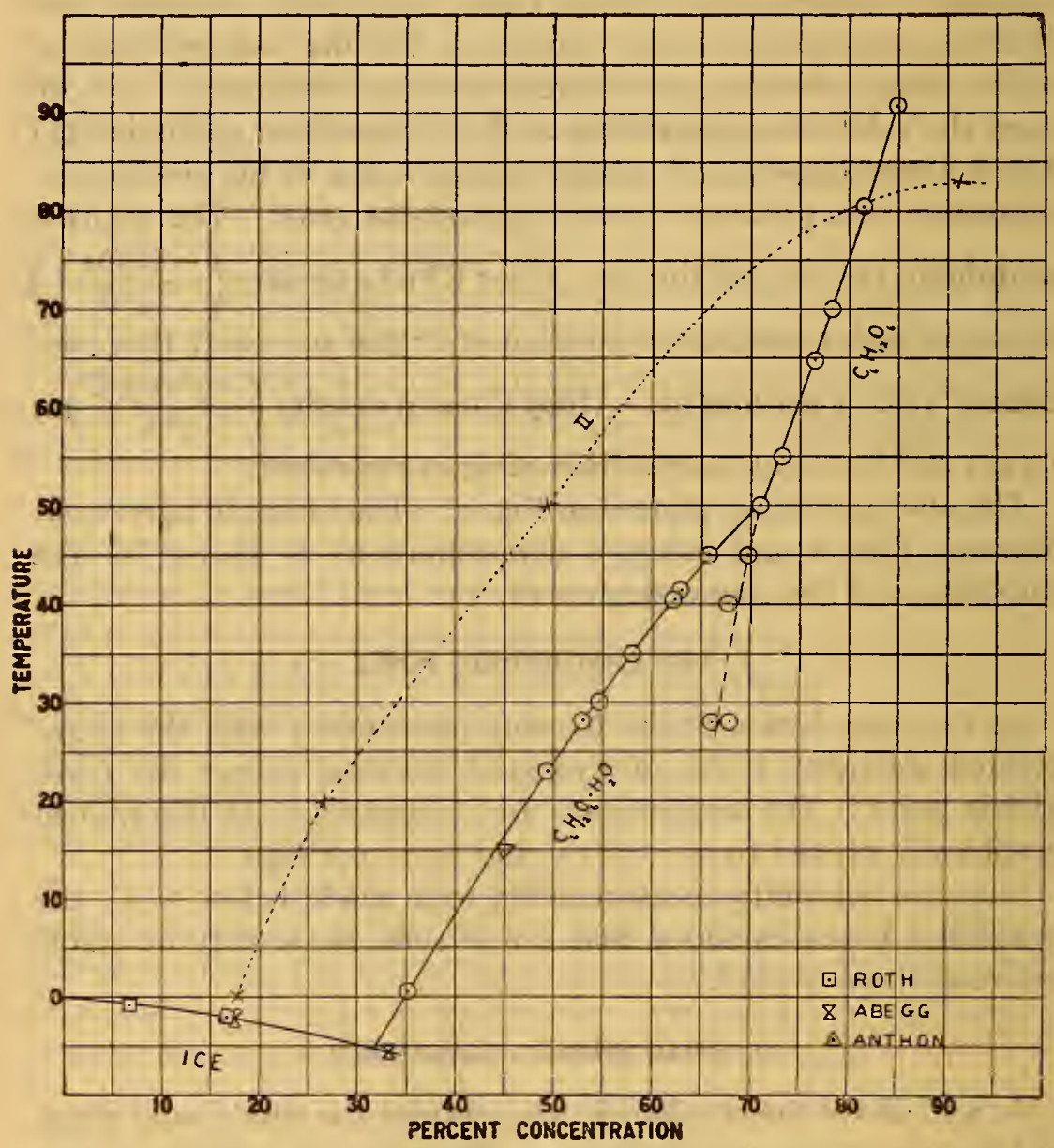

FIG. 2.-The system, dextrose and water

The solid curves show the final equilibria with respect to the solid phases, ice, dextrose hydrate, and anhydrous dextrose. The dotted curve shows the instaneous solubility before mutarotation. All data are expressed in terms of anhydrous dextrose.

The temperature coefficient of the solubility is very large. Thus, if the solubilities in Table $\mathrm{I}$ are stated in terms of the parts of dextrose dissolved by a constant weight of water, it is seen that $100 \mathrm{~g}$ of water dissolve, at $0{ }_{5} \mathrm{C}, 54.32$; at $30^{\circ} \mathrm{C}$, I 20.46; and at $50^{\circ} \mathrm{C}, 243.76 \mathrm{~g}$ of dextrose. 
TABLE 1.-The Solubility of Dextrose in Pure Water

\begin{tabular}{|c|c|c|c|c|c|}
\hline $\begin{array}{c}\text { Temperature in degrees } \\
\text { centigrade }\end{array}$ & Solid phase & $\begin{array}{c}\text { Dextrose } \\
\text { in solu- } \\
\text { tion } a\end{array}$ & $\begin{array}{c}\text { Temperature in degrees } \\
\text { centigrade }\end{array}$ & Solid phase & $\begin{array}{c}\text { Destrose } \\
\text { in solu- } \\
\text { tion a }\end{array}$ \\
\hline 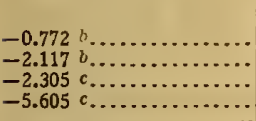 & Ice & $\left\{\begin{array}{r}\text { Per cent } \\
6.83 \\
16.65 \\
17.59 \\
33.02\end{array}\right.$ & $\begin{array}{l}28.00 \ldots \ldots \ldots \ldots \\
28.00 \ldots \ldots \ldots \ldots \ldots \ldots \\
40.00 \ldots \ldots \ldots \ldots \ldots \ldots \\
45.00 \ldots \ldots \ldots \ldots \ldots \ldots\end{array}$ & $\left\{\begin{array}{l}\alpha-\mathrm{C}_{6} \mathbf{H}_{12} \mathrm{O}_{6} \\
\text { Metastable }\end{array}\right.$ & $\begin{array}{l}\text { Per cent } \\
66.0 \\
67.9 \\
67.6 \\
69.69\end{array}$ \\
\hline$-5.3 \ldots \ldots \ldots \ldots \ldots \ldots$ & Cryohydrate & 31.75 & \multirow{3}{*}{ 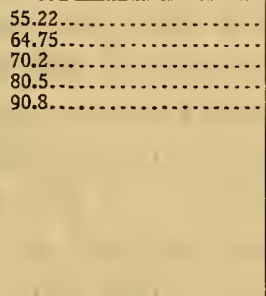 } & \multirow{3}{*}{$\alpha-\mathrm{C}_{6} \mathrm{H}_{12} \mathrm{O}_{6}$} & \multirow{3}{*}{$\begin{array}{l}73.08 \\
76.36 \\
78.23 \\
81.49 \\
84.90\end{array}$} \\
\hline 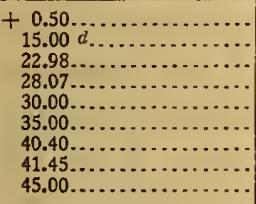 & $\alpha-\mathrm{C}_{6} \mathrm{H}_{12} \mathrm{O}_{5} \cdot \mathrm{H}_{2} \mathrm{O}$ & $\begin{array}{l}35.2 \\
44.96 \\
49.37 \\
52.99 \\
54.64 \\
58.02 \\
62.13 \\
62.82 \\
65.71\end{array}$ & & & \\
\hline $50.00 \ldots \ldots \ldots$ & Transitlon & 70.91 & & & \\
\hline
\end{tabular}

c Estimated as anhydrous sugar.

$b$ Roth, Zeit. Phys. Chem., 43, p. 552 ; 1903.

c Abegg, Zeit. Phys. Chem., 15, p. 222; I894.

d Anthon, v. I,ippmannn, Die Chemie der Zuckerarten, I, p. 266; I894.

\section{THE MELTING POINT OF DEXTROSE HYDRATE}

The melting point of dextrose hydrate as observed in a capillary tube in the usual manner has been found to lie in the vicinity of $80-90^{\circ} \mathrm{C}$, the values reported by different observers ${ }^{7}$ being strikingly at variance with one another. We have found that if the capillary containing the sample is plunged into the bath which had previously been brought to about $83^{\circ} \mathrm{C}$, incipient fusion occurred, although it was found impossible to obtain reproducible results.

At its melting point dextrose hydrate is in equilibrium with a solution of its own composition. In other words, the solubility as thus determined is 90.9 per cent at $80-85^{\circ} \mathrm{C}$. It is at once apparent from Fig. 2 that by no manner of extrapolation can our solubility curve of the hydrate be made to pass through this point, and that the discrepancy is so great that some explanation is required.

When crystalline dextrose is dissolved in water, it immediately undergoes a partial stereochemical transformation into the $\beta$-form at a rate which depends upon the temperature. All of the present measurements were made under equilibrium conditions, the time of agitation of the crystals being continued until the reaction,

$$
\underset{\text { crystals }}{\alpha} \underset{\text { saturated solution }}{\rightleftharpoons} \underset{\text { solution }}{\rightleftharpoons} \underset{\text {-dextrose }}{\rightleftharpoons \text { dextrose }}
$$

\footnotetext{
7 V. Lippmann, Die Chemie der Zuckerarten, I, p. 263; 1904.
} 
had reached equilibrium. The final solubility is consequently that of $\alpha$-dextrose, not in water, but in a solution of $\beta$-dextrose. On the other hand, at the melting point or the temperature of incipient fusion, the composition of the crystals represents the solubility of $\alpha$-dextrose in water, since no $\beta$-dextrose can be formed until after the crystal has begun to fuse. Even after fusion the complete transformation to the equilibrium requires several minutes, during which time the melting point is undergoing rapid variation, both because of the formation of the $\beta$-compound and because of the rapid efflorescence of the hydrate. With these two disturbing effects, it is not surprising that the melting point should fail of reproducibility. It is now of interest to inquire if, on the basis of the above discussion, we may reconcile our solubility curve with the observed melting point. If we could plot the solubility curve of $\alpha$-dextrose hydrate in pure water-that is, the instantaneous solubility before mutarotation has begun-such a curve should pass through the observed melting point.

On this curve two points are experimentally realizable. One of these is the melting point itself. The other point is the instantaneous solubility at $0^{\circ} \mathrm{C}$. The possibility of obtaining experimental data at $0^{\circ} \mathrm{C}$ depends upon the fact that the rate of mutarotation is an important function of temperature. Thus the velocity constant of mutarotation which, expressed in decimal logarithms and minutes, is $0.00662^{8}$ at $20.7 \mathrm{C}$, becomes about the order of $0.00 \mathrm{I}$ at $\mathrm{o}^{\circ} \mathrm{C} .{ }^{\circ}$ The reaction being so slow, it is possible to obtain a solubility measurement of the pure $\alpha$-hydrate in water before its transformation has become considerable by violently agitating a large excess of solid phase in the presence of its solution for short periods of time. The mean of three such determinations which were in agreement within 3 per cent indicated that the instantaneous solubility was 17.5 per cent.

A concentrated aqueous solution of dextrose after the completion of the mutarotation contains the two isomers ${ }^{10}$ in the ratio of about 40 per cent $\alpha$ - and 60 per cent $\beta$-. We may therefore from our solubility measurements make an approximate calculation of the solubility of the $\alpha$-dextrose in pure aqueous solution. An example will suffice.

At $20^{\circ} \mathrm{C}$ the final solubility is 47.5 per cent. One hundred grams of the solution then contains $19.0 \mathrm{~g} \alpha$-dextrose, $28.5 \mathrm{~g}$

8 Ievy, Zeit. Phys. Chem., 17, p. 301 ; 1805.

9 Nelson and Beegle, J. Amer. Chem. Soc., 41, p. 565; r9r9, report 0.00092 at $0 .{ }^{\circ}{ }_{15}$ C. and prr 6.84 .

${ }^{10}$ Armstrong, The simple carbohydrates and glucosides, p. 17; 1919. Hudson, J. Amer. Chem. Soc., 89, p. I018; 1917 . 
$\beta$-dextrose, and $52.5 \mathrm{~g}$ water. We find the solubility of the $\alpha$-form in pure water to be about 26.6 per cent. Proceeding in this way we may compute roughly the solubilities of the $\alpha$ dextrose in pure water, as shown in the dotted curve II. This curve, which is obviously little more than qualitative in character, is seen to be compatible with the observed melting point of $80-85^{\circ} \mathrm{C}$.

\section{THE TRANSITION POINT}

At $50^{\circ} \mathrm{C}$ duplicate measurements were made of the solubility approached from supersaturation and from undersaturation, respectively. The solubility proved to be 71.06 per cent. The solid phases from which samples of the solution had been taken were rapidly purged with aqueous alcohol followed by ether. They were then air died and analyzed for their water content. One of these was completely anhydrous; the other contained exactly one molecule of water of crystallization. Since these two solid phases were in equilibrium with solutions of the same composition at the same temperature, it is evident that the temperature of $50^{\circ} \mathrm{C}$ is the "transition point" from the hydrated to the anhydrous crystalline form, in the presence of the solution. It should, however, be remarked that this is only a pseudo-transition point. The true transition point would be that temperature at which $\alpha$-dextrose is in equilibrium with a solution containing only $\alpha$-dextrose. The solution actually contains about 60 per cent of $\beta$-dextrose, which thus lowers the true transition point by a perfectly definite amount. The true transition temperature would be of so fugitive a character that its measurement not only would involve great experimental difficulties, but would be of little practical significance.

\section{THE SOLID PHASE; $\alpha-\mathrm{C}_{6} \mathrm{H}_{12} \mathrm{O}_{6}$}

At temperatures above $50^{\circ} \mathrm{C}$ anhydrous dextrose becomes the stable solid phase. Its solubility rises in very nearly linear relation and, compared with that of the hydrate, with a small temperature coefficient. It forms hard crystals which are capable of development to a considerable size. The solubility measurements are assembled in Table $I$ and plotted in Fig. 2.

The solubility curve produced to the 100 per cent ordinate shows a melting point for the anhydrous form below $135^{\circ} \mathrm{C}$, whereas the observed melting point is $144^{-1} 46^{\circ} \mathrm{C} .{ }^{11}$ Here again

${ }^{11}$ Maquenne, L.es sucres et principaux dérivés, p. 478; 1900. 
the melting point, as indicated by extension of the solubility curve, is that of the mixture of $\alpha$ - and $\beta$-dextrose, while the observed is that of the pure $\alpha$-dextrose.

Below the transition temperature it is possible to maintain the anhydrous form as the solid phase in a metastable state. We have succeeded in extending the solubility measurements down to $28^{\circ} \mathrm{C}$. Our data on this branch of the curve must be considered approximate, since the experimental difficulties were considerable.

In the vicinity of $100^{\circ} \mathrm{C}$ the anhydrous $\beta$-dextrose becomes the stable solid phase. We have not attempted to determine the transformation point or the solubilities. It is possible to predict, however, that the solubility curve of the $\beta$-compound lies very close to the prolongation of the $\alpha$-, since their observed melting points are very close together. The $\beta$-dextrose melts at $148^{\circ} \mathrm{C}$, the $\alpha$-at $146^{\circ} \mathrm{C}$.

\section{SUMMARY}

The equilibria in the system, dextrose and water have been determined. For temperatures below $90^{\circ} \mathrm{C}$ three solid phases are capable of existence, namely, ice, $\alpha$-dextrose monohydrate, and anhydrous $\alpha$-dextrose. The freezing point curve was computed from the data of Roth and of Abegg. The cryohydric point, determined graphically, was found to lie at the temperature $-5 \cdot 3 \mathrm{C}$ and concentration $3 \mathbf{I} .75$ per cent dextrose. The solid phase, $\alpha$-dextrose monohydrate, which occurs in lustrous plates, is stable between $-5^{\circ} 3 \mathrm{C}$ and $50^{\circ} \mathrm{C}$. Its solubility shows a very high temperature coefficient. Thus, at $0: 5 \mathrm{C}$, Ioo parts of water dissolve 54.32 parts; at $50^{\circ} \mathrm{C}, 243.76$ parts of dextrose. The observed melting point, $80-90^{\circ} \mathrm{C}$, although located far from the extrapolated solubility curve, is shown to be compatible with the measurements, on the theory that $\beta$-dextrose is present in the saturated solution and absent during a melting point determination. Above the transition point, $50^{\circ} \mathrm{C}$, the anhydrous form becomes stable. Its solubility shows a small temperature coefficient. The solubility measurements of this phase in metastable state were continued down to $28^{\circ} \mathrm{C}$.

WASHINGTON, January 7, 1922. 